\title{
In vivo Evaluation of the Antagonistic Effect of Lactobacillus acidophilus against Propionobacterium acnes in the Treatment of Acne
}

\author{
Tatiana de los Angeles Mosquera Tayupanta* $(\mathbb{D}$ and \\ Victoria Sheila Pumisacho Ocana \\ Universidad Politecnica Salesiana, BIOARN Research Group, Pichincha - 170525. Quito, Ecuador.
}

\begin{abstract}
Probiotics are able to inhibit certain pathogens, their use to fight acne caused by the proliferation of Propionibacterium acnes, would be an alternative in topical bacteriotherapy. There are studies of in vitro antagonism ${ }^{1}$. This study in vivo the antagonistic capacity of Lactobacillus acidophilus against Propionibacterium acnes in young people from 15 to 20 years old, with previous diagnosis of type II acne. First the evaluation of the in vitro antagonistic effect of Lactobacillus acidophilus against Propionibacterium acnes was performed. The measurement of the inhibition halos determined the concentration with antagonist effect $1 \times 10^{8} \mathrm{cfu} / \mathrm{ml}$, with this concentration four formulations were tested, of these four only one had an in vitro effect; this formulation was subjected to a test of irritability (Mexican standard Nom-039-SSA1-1993) IPC $=0.19$ defines the formula as "well tolerated", the study of cosmetic activity in vivo was performed with a non-invasive method of exploration, using the Visiopor PP $34 N^{\circledR}$ bioengineering instrument as a result, a 48-hour decrease in average porphyrins of $78.3 \%$ was obtained in the total number of treated individuals, which implies a decrease in the population of $P$. acnes, the acne-causing agent.
\end{abstract}

Keywords: Acne, antagonist effect, Lactobacillus acidophilus, Propionibacterium acnes.

\footnotetext{
*Correspondence: tmosquera@ups.edu.ec; +59323962800

(Received: 20 June 2019; accepted: 18 July 2019)

Citation: Tatiana de los Angeles Mosquera Tayupanta and Victoria Sheila Pumisacho Ocana, In vivo Evaluation of the Antagonistic Effect of Lactobacillus acidophilus against Propionobacterium acnes in the Treatment of Acne, J Pure Appl Microbiol., 2019; 13(3): 1317-1324. https://doi.org/10.22207/JPAM.13.3.03

(C) The Author(s) 2019. Open Access. This article is distributed under the terms of the Creative Commons Attribution 4.0 International License which permits unrestricted use, sharing, distribution, and reproduction in any medium, provided you give appropriate credit to the original author(s) and the source, provide a link to the Creative Commons license, and indicate if changes were made.
} 


\section{INTRODUCTION}

Lactic acid of Streptococcus thermophilus, a bacterium found in yoghurts has specific benefits in the skin, because it can increase the production of ceramide when applied to the skin for 7 days $^{2}$. It has been reported that this bacterium possesses mainly some of the sphingolipids of this ceramide, especially phytosphingosine (PS), which provide antimicrobial activity against $P$. acnes, which would be of great interest for the treatment of $a_{c n e}{ }^{3}$. Other researches carried out have shown that numerous probiotic bacteria can provide antimicrobial in vitro activity against $P$. acnes, as is the case of Enterococcus faecalis SL-5 which when applied topically through a lotion for 8 weeks reduces inflammatory lesions caused by $P$. acnes by more than $50 \%$ compared to placebo ${ }^{4}$. There is no detailed information on the antagonistic activity of Lactobacillus acidophilus against $P$. acnes, however, there is an in vitro study of the ability of probiotic bacteria to inhibit acne produced by $P$. acnes, such as that performed by Al-Ghazzewi and Tester (2010), who studied four strains of Lactobacilli (mostly of human origin), Lactobacillus casei ssp. casei NCFB161, Lactobacillus acidophilus NCFB 7148, Lactobacillus plantarum DSM 12028, Lactobacillus gasseri NCFB 2233 and a Lactococcus strain (Lactococcus lactis ssp. lactis NCIMB 6681) which showed a significant inhibition in the growth of $P$. acnes NCTC737, but inhibition concentrations were not defined, and were not tested in vivo ${ }^{5}$.

Once the antagonistic activity is demonstrated, it is necessary to incorporate the probiotic into a cosmetic formulation to prove the antagonistic capacity of Lactobacillus acidophilus; the efficacy of the formula will be verified by the reduction of porphyrins in the treated skin, an aspect directly related to the decrease in the population of $P$. acnes in individuals, a result that allows promoting the use of probiotic as an alternative In the treatment of acne.

\section{MATERIALS AND METHODS \\ Biological Material \\ Lactobacillus acidophilus ATCC ${ }^{\circledR} 4356$ \\ (probiotic lactic bacteria) \\ Propionibacterium acnes ATCC ${ }^{\circledR} 11827$ \\ Antagonism tests}

Pathogenic bacterium inoculum ( $P$. acnes ATCC $^{\circledR}$ 11827) $(100 \mu l)$ was inoculated in Mann
Rogosa Sharp agar (MRS, BioCen); Whatmann discs of $6 \mathrm{~mm}$ diameter were placed in in the dry agar antibiogram type, on each one were added $10 \mathrm{ml}$ of three different concentrations of $L$. acidophilus ATCC $^{\circledR}$ 4356. The second antagonism test was carried out with the cosmetic formulations, in which the concentration with the best antagonism of the first stage was incorporated. The boxes were placed in inverted position inside the anaerobic incubator at $37^{\circ} \mathrm{C}$ in $5 \%$ of $\mathrm{CO}_{2}$ for 72 hours. This test was determined as positive when grow was presented around the antibiogram disk.

\section{Elaboration of the Cosmetic Formula}

Cosmetic form is defined as a lotion with the least number of ingredients to evaluate the efficacy of the element considered as active in the formulation $1 \times 10^{8} \mathrm{cfu} / \mathrm{ml}$ of Lactobacillus acidophilus, the other Ingredients are specified in table 1.

Table 1. Ingredients of the cosmetic lotion

\begin{tabular}{|c|c|c|}
\hline $\begin{array}{l}\text { Ingredient } \\
\text { (INCI) }\end{array}$ & Role & $\begin{array}{l}\text { Use } \\
\text { percentage }\end{array}$ \\
\hline Glycerin & Moisturizer agent & $10-30 \%$ \\
\hline $\begin{array}{l}\text { Cellulose } \\
\text { gum }\end{array}$ & Emulgent agent & $0,25-1 \%$ \\
\hline $\begin{array}{l}\text { Distilled } \\
\text { water }\end{array}$ & Vehicle & e.c.f \\
\hline
\end{tabular}

*e.c.f. = enough quantity for

Four formulas were tested based on an experimental design that combined the concentrations of the two excipients of the formula; i $2 \times 2$ experimental factorial design was done.

Evaluation of the dermal safety of the lotion (irritability test)

All in vivo tests were carried out considering the ethical criteria of the research in human beings, and from the selection process all the volunteers were informed about: risk-benefit, confidentiality and informed consent.

The procedure for applying the patch Test was based on the official Mexican standard Nom-039-SSA1-1993 with human induction patch tests, bringing the cosmetic sample into contact with the person's skin to measure dermal irritation and sensitivity; the results were valued according to a numerical scale that is averaged, the average 
represents the irritation average index (I.A.I) which is an useful index to assess the damage that can present the products applied on the skin?

In vivo evaluation: efficiency of the cosmetic formula

A non-invasive methodology was performed by using a bioengineering team Visiopor PP34 ${ }^{\circledR}$ which quantifies the number of porphyrins per $\mathrm{cm}^{2}$, and a mathematical analysis that determines the reduction of porphyrins directly related to the decrease of $P$. acnes. The selection of the voluntary individuals was made based on the inclusion and exclusion criteria, the dermatological clinical evaluation that identified twenty adolescents diagnosed with acne type II; the volunteers filled out a file with their personal data and clinical background and the informed consent letter.

\section{Ethical considerations in the in vivo study}

The investigation complied with all the parameters established in the Organic Health Law of Republic of Ecuador, in which is established in the Art. 208 that any scientific technological research in health must be subjected to bioethical and rights principles, prior informed and written consent and respecting confidentiality ${ }^{8}$. In terms of respecting these bioethical principles, the research process was based on three principles: autonomy, beneficence and not maleficence. Being understood autonomy as the recognition of people to choose rationally and to govern their own body according to their own interest to the extent of their possibilities; in this sense the decisions are around the capacities of the subject under study and not on the investigator ${ }^{9}$; based on this principle each voluntary subject of study was timely and pedagogically informed about the procedure to follow, its implications in the short, medium and long term, the benefits and risks of the procedure and on the possibility of leaving at any time of the study, to ensure this principle was handled the "Confidentiality Agreements" and "informed consent". The beneficence is understood as the obligation that the investigator has to act for the benefit of the subject under investigation, helping the individual to promote his/her legitimate interests ${ }^{10}$. To fulfill both the principle of beneficence and non-maleficence, the research was managed with a "research protocol" which raised the risks involved in the study, risks that are few by being a non-invasive therapy, on the contrary, therapy with a lot of benefits for the volunteer subjects who were presented this alternative to improve their skin pathology.

\section{RESULTS AND DISCUSSION \\ In vitro antagonism test}

The results of the antagonism test are shown in Table 2 as well as the averages of the inhibition halos and the inhibition area or free area.

Sterile water was used as negative white and an antibiotic (tetracycline) as a positive white.

Table 2. Inhibition halos of Lactobacillus acidophilus ATCC ${ }^{\circledR} 4356$ against Propionibacterium acnes ATCC $^{\circledR} 11827$

\begin{tabular}{lcc}
\hline $\begin{array}{l}\text { Lactobacillus } \\
\text { acidophilus } \\
\text { (cfu/ml) } \\
\text { conce. }\end{array}$ & $\begin{array}{c}\text { Average of } \\
\text { inhibition } \\
\text { halos }(\mathrm{mm})\end{array}$ & $\begin{array}{c}\text { Inhibition area } \\
\text { (inhibition halo- } \\
\text { antibiogram } \\
\text { disc) }(\mathrm{mm})\end{array}$ \\
\hline $1 \times 10^{8}$ & 9.8 & 3.8 \\
$1 \times 10^{7}$ & 6.3 & 0.3 \\
$1 \times 10^{6}$ & 6 & 0 \\
$\begin{array}{l}\text { BP (positive } \\
\text { white) }\end{array}$ & 37.4 & 31.4 \\
$\begin{array}{l}\text { BN (negative } \\
\text { white) }\end{array}$ & 6 & 0 \\
\hline
\end{tabular}

Table 3. Cosmetic formulas (lotions) with L. acidophilus

\begin{tabular}{lcccc}
\hline Components & Lotion A & Lotion B & Lotion C & Lotion D \\
\hline L. acidophilus & $1 \times 10^{8} \mathrm{cfu} / \mathrm{ml}$ & $1 \times 10^{8} \mathrm{cfu} / \mathrm{ml}$ & $1 \times 10^{8} \mathrm{cfu} / \mathrm{ml}$ & $1 \times 10^{8} \mathrm{cfu} / \mathrm{ml}$ \\
Glycerin & $10 \%$ & $10 \%$ & $30 \%$ & $30 \%$ \\
Cellulose gum & $0.25 \%$ & $1 \%$ & $0.25 \%$ & $1 \%$ \\
Distilled water & e.c.f. & e.c.f. & e.c.f. & e.c.f. \\
\hline
\end{tabular}

${ }^{*} \mathrm{cfu}=$ colony forming units 
According to the results, Lactobacillus acidophilus showed certain tendency to inhibit the pathogen from a concentration of $1 \times 10^{7} \mathrm{cfu} / \mathrm{ml}$; however, the concentration that presented higher inhibitory activity was $1 \times 10^{8} \mathrm{cfu} / \mathrm{ml}$, with an inhibition area higher than $1 \mathrm{~mm}$ around the disc, which was determined as a positive antagonistic effect.

The antagonistic effect obtained against $P$. acnes (Gram-positive bacteria) was less than the expected with respect to the inhibition obtained in various studies against other pathogenic microorganisms, this may be because lactic bacteria exert more antagonistic activity against gram-negative bacteria compared to grampositive bacteria, mainly because gram-negative bacteria have an external membrane containing phospholipids, lipopolysaccharides and proteins that traverse the wall in all its thickness, delimiting hydrophilic pores that allow the passage of substances with low molecular weight so the sensitivity is different ${ }^{11}$.

\section{Statistical analysis of inhibition halos generated} by Lactobacillus acidophilus ATCC ${ }^{\circledR} 4356$

Fig. 1 shows the concentration mean of $1 \times 10^{8}$, which is 9.8 , and the interquartile range is 0.7 ; the concentration median of the 1 $x 10^{7}$ is 6.35 , and the Interquartile range is 0.52 ;

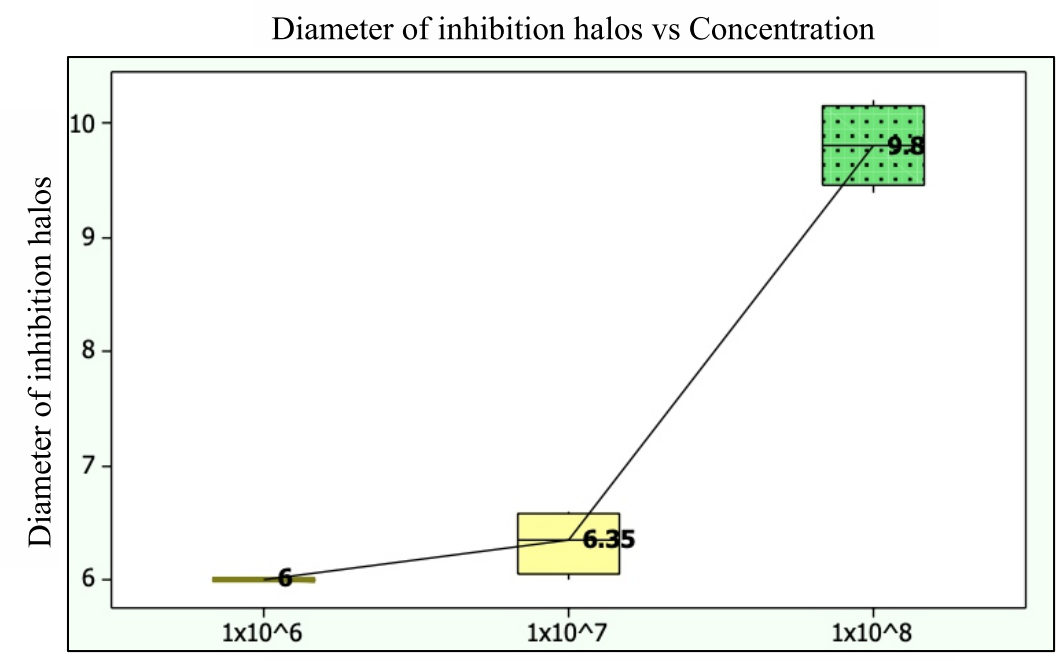

Fig. 1. Box plot of inhibition halos diameter vs the concentration of Lactobacillus acidophilus carried out in MINITAB 1.6 .

the concentration mean of $1 \times 10^{6}$ is 6 , and the Interquartile range is 0 .

The tendency line increased from the concentration $1 \times 10^{6}$ to the concentration $1 \times 10^{8}$, indicating that the lowest the concentration of $L$. acidophilus is the diameter of the inhibition halo.

To determine which of the concentrations causes the difference of the halos, a post-test was carried out in which the means of all the possible concentration pairs (Kruskal-Wallis All-Pairwise Comparisons test) were obtained, from which the following results were obtained and are shown in Figure 2.

According to the results presented in Figure 2, there are two groups of concentrations which are statistically related to each other. These groups are: Group A: $1 \times 10^{8} \mathrm{cfu} / \mathrm{ml}, 1 \times 10^{7} \mathrm{cfu} / \mathrm{ml}$ and group B: $1 \times 10^{7} \mathrm{cfu} / \mathrm{ml}, 1 \times 10^{6} \mathrm{cfu} / \mathrm{ml}$.

The concentration that that stands out from the two groups that were formed is $1 \times 10^{8} \mathrm{cfu} /$ $\mathrm{ml}$, because it had a higher mean average (10500). Therefore, it is concluded that it presents the best inhibition halos.

\section{Elaboration of cosmetic formulas and in vitro antagonism tests}

According to the $2 \times 2$ experimental design, four formulas were generated and are presented on Table 3; these formulas were done to carry out the in vitro antagonism test and to ensure that the incorporation of excipients in the formula not affect the antagonistic activity of $L$. acidophilus. 


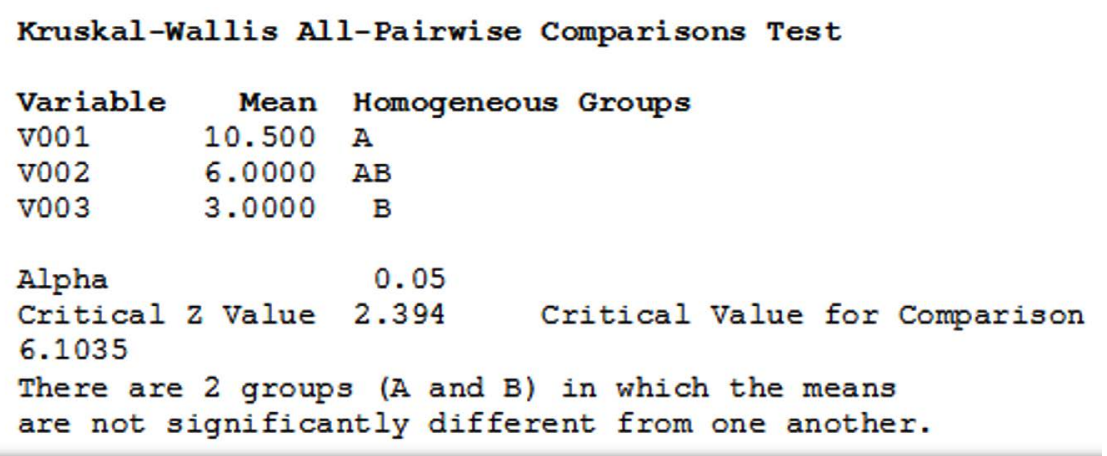

Fig. 2. Kruskal-Wallis All-Pairwise Comparisons Test of Lactobacillus acidophilus ATCC ${ }^{\circledR} 4356$ concentrations against Propionibacterium acnes ATCC ${ }^{\circledR} 11827$.

The inhibition halos of lotions formulated with $L$. acidophilus are presented in Table 4, formulas A, B, C or D without $L$. acidophilus are considered as a negative white, that is, only the excipients of each formulation.

Table 4. Mean of inhibition halos $(\mathrm{mm})$ of cosmetic formulas with L. acidophilus

\begin{tabular}{lc}
\hline Formula & $\begin{array}{c}\text { Average of } \\
\text { inhibition } \\
\text { halos (mm) }\end{array}$ \\
\hline Lotion A & 9.6 \\
Lotion B & 8.5 \\
Lotion C & 8.2 \\
Lotion D & 6.3 \\
Negative White & 6.0 \\
(A, B, C, D) & \\
\hline
\end{tabular}

\section{Statistical analysis of inhibition halos of cosmetic formulations}

In figure 3 is determined that the median diameter of the inhibition halo was higher for lotion A (9.6), this lotion also demonstrated the least variability, with an interquartile range of 0.37. In addition, the distribution had a negative asymmetry. Lotions $B$ and $C$ had median diameters of similar inhibition halos (8.5 and 8.2, respectively). In addition, lotion $\mathrm{C}$ also showed the highest variability, with a median interquartile range of 0.85 . Halos diameter of lotion inhibition $D$ was only 6.25 with an interquartile range of 0.65 . The BN median of each of the lotions was 6 , indicating there is no type of inhibition.

Kruskal-Wallis $(\mathrm{H})$ statistic value was 13.0336, and the probability value associated with

Inhibition vs Lotion

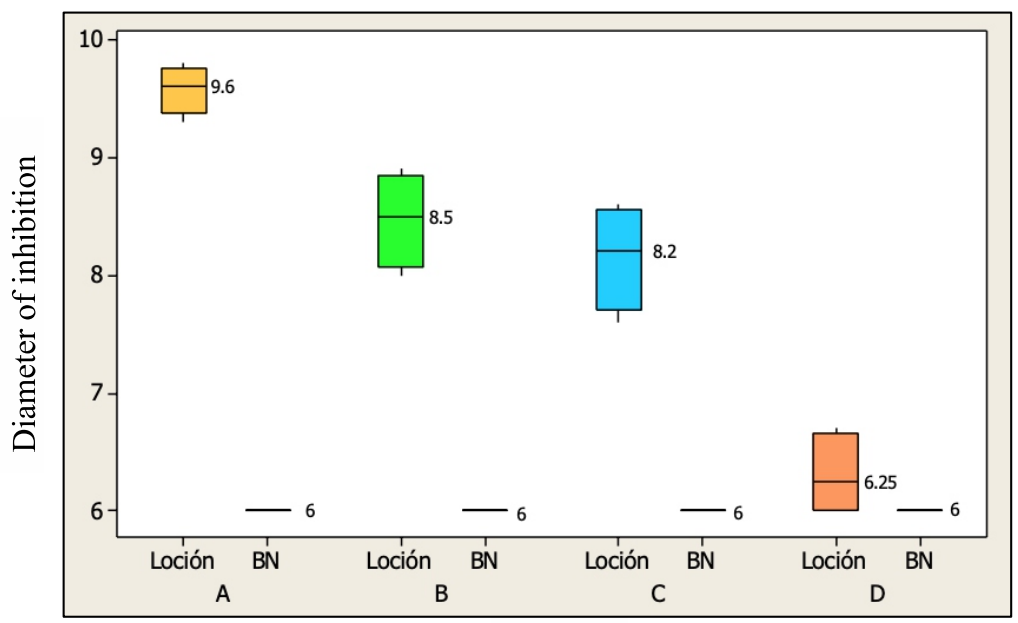

Fig. 3. Box plot of inhibition diameter vs experimental lotions, made in MINITAB 1.6. 


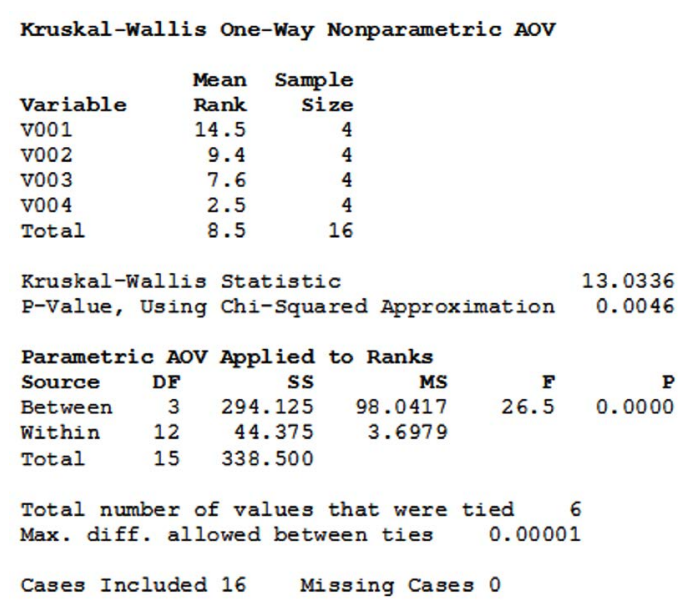

Fig. 4. Kruskal-Wallis Test for four lotions with Lactobacillus acidophilus ATCC $^{\circledR} 4356$ against Propionibacterium acnes ATCC ${ }^{\circledR} 11827$.

the statistic $(P)$ was 0.0046 . The probability value associated with the statistic $(P)$ was less than the chosen Alpha (0.05); for this reason, the alternative hypothesis is accepted and it is concluded that at least one of the lotions generated an inhibition halo different from the others.

In order to determine the lotion generated different inhibition halos, a posteriori test was performed in which the medians of all possible pairs of lotions (Kruskal-Wallis All-Pairwise Comparisons test) were compared, from which were obtained the following results, which are presented in Figure 5.

There are two groups of lotions which are statistically similar. These groups are: Group A: lotion A, lotion B, lotion C and Group B: lotion
B, lotion C, lotion D. When comparing the groups, it was observed that the lotion with the highest medium range is lotion $A$, with a median range of 14,500 , considering the one with most antagonistic effect; so it was used in the study of cosmetic activity in vivo.

\section{Evaluation of the dermal safety of the lotion (irritability test)}

The I.A.I. of lotion A was 0.19, the standard identifies that if the I.A.I is between $>0$ and $\leq 0.5$ it qualifies as a "well tolerated" product that can be safely used, and in the specific case of this investigation it was suitable to continue with the efficacy study in vivo.

\section{In vivo evaluation: efficacy of the cosmetic} formula

After the timely application of lotion A in acne lesions for 2 consecutive days, the amount of porphyrins was quantified at the beginning, 24 hours later and at 48 hours in volunteered adolescents using the Visiopor PP34N ${ }^{\circledR}$ team.

Table 5 shows that there was a decrease in porphyrins since the first application of the formulated lotion; a maximum decrease of $100 \%$ was obtained 48 hours after the application, and a minimum of $45.5 \%$, and a total average of $78.3 \%$, indicating that lotion $A$ had antagonistic effect against $P$. acnes in vivo.

As shown in Figure 6, all adolescents in the study showed a porphyrins reduction of more than $40 \%$. Eight out of the 20 individuals showed higher percentage decrease in a range of $90 \%$ $100 \%$.

\section{Kruskal-Wallis All-Pairwise Comparisons Test

$\begin{array}{lrl}\text { Variable } & \text { Mean } & \text { Homogeneous Groups } \\ \text { v001 } & 14.500 & \text { A } \\ \text { V002 } & 9.3750 & \text { AB } \\ \text { V003 } & 7.6250 & \text { AB } \\ \text { v004 } & 2.5000 & \text { B }\end{array}$

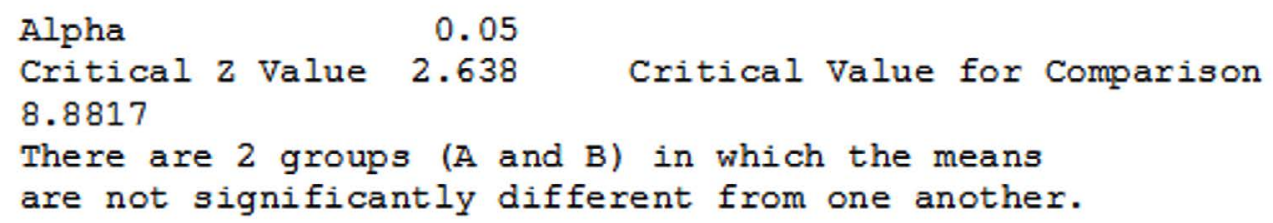

Fig. 5. Kruskal-Wallis All-Pairwise Comparisons Test for the four lotions with Lactobacillus acidophilus ATCC ${ }^{\circledR} 4356$ against Propionibacterium acnes ATCC ${ }^{\circledR} 11827$. 
Table 5. Reduction percentage of porphyrins generated by $P$. acnes after the application of lotion A.

\begin{tabular}{|c|c|c|c|c|c|}
\hline $\begin{array}{l}\text { Volunteer } \\
\mathrm{N}^{0}\end{array}$ & $\begin{array}{c}\text { Initial } \\
\text { evaluation } \\
\text { ( } \mathrm{N}^{0} \text { of porphyrins) }\end{array}$ & $\begin{array}{c}\text { Evaluation } 24 \\
\text { hours later } \\
\text { ( } \mathrm{N}^{0} \text { of porphyrins) }\end{array}$ & $\begin{array}{l}\text { Final evaluation } \\
48 \text { hours later } \\
\text { ( } \mathrm{N}^{0} \text { of porphyrins) }\end{array}$ & $\begin{array}{c}\text { Reduction } \\
\text { of porphyrins }\end{array}$ & $\begin{array}{l}\text { Reduction } \\
\% \text { of } \\
\text { porphyrins }\end{array}$ \\
\hline 1 & 7 & 5 & 3 & 4 & 57.1 \\
\hline 2 & 2 & 0 & 0 & 2 & 100 \\
\hline 3 & 8 & 4 & 2 & 6 & 75 \\
\hline 4 & 11 & 8 & 3 & 8 & 72.7 \\
\hline 5 & 22 & 14 & 12 & 10 & 45.5 \\
\hline 6 & 8 & 5 & 3 & 5 & 62.5 \\
\hline 7 & 4 & 3 & 2 & 2 & 50 \\
\hline 8 & 7 & 4 & 0 & 7 & 100 \\
\hline 9 & 8 & 4 & 1 & 7 & 87.5 \\
\hline 10 & 16 & 4 & 2 & 14 & 87.5 \\
\hline 11 & 3 & 2 & 1 & 2 & 66.7 \\
\hline 12 & 1 & 0 & 0 & 1 & 100 \\
\hline 13 & 2 & 1 & 1 & 1 & 50 \\
\hline 14 & 4 & 4 & 2 & 2 & 50 \\
\hline 15 & 21 & 14 & 7 & 14 & 66.7 \\
\hline 16 & 5 & 3 & 0 & 5 & 100 \\
\hline 17 & 13 & 8 & 0 & 13 & 100 \\
\hline 18 & 1 & 1 & 0 & 1 & 100 \\
\hline 19 & 1 & 0 & 0 & 1 & 100 \\
\hline 20 & 21 & 16 & 1 & 20 & 100 \\
\hline
\end{tabular}

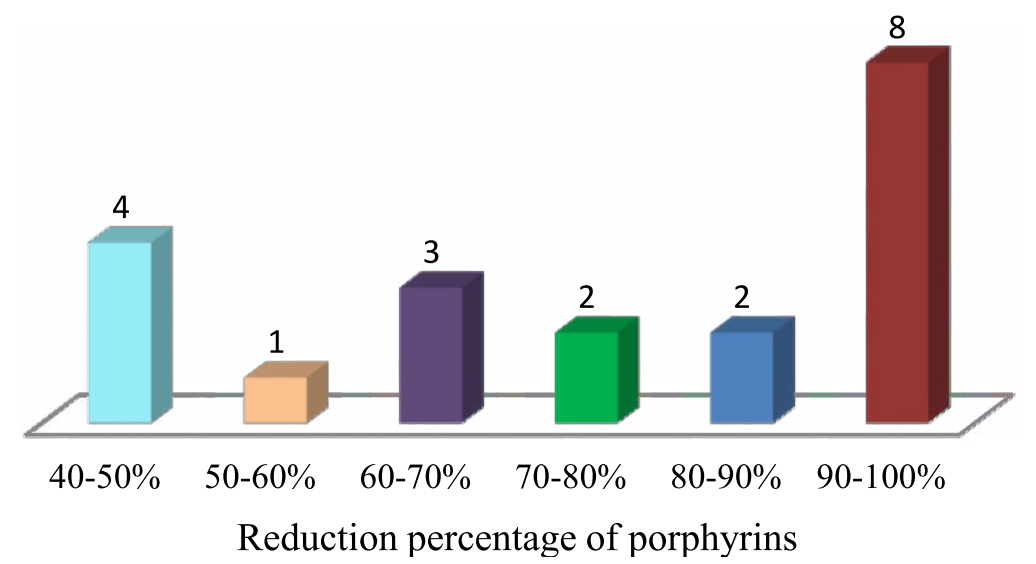

Fig. 6. Number of adolescents vs. reduction percentage of Porphyrins.

\section{CONCLUSIONS}

It is concluded that at a higher concentration of $L$. acidophilus higher in vitro antagonistic capacity compared to $P$. acnes; a concentration of $1 \times 10^{8} \mathrm{cfu} / \mathrm{ml}$ achieved higher inhibition than a concentration of $1 \times 10^{6} \mathrm{cfu} / \mathrm{ml}$. From the four lotions evaluated $(A, B, C, D)$ the one that presented higher in vitro antagonistic activity compared to $P$. acnes was lotion $A$. The irritability study determined the formula as a well-tolerated product with an I.A.I equal to 0.19 that qualifies it as a skin-safe product. The in vivo study of cosmetic activity showed the antagonistic activity against $P$. acnes in vivo, obtaining a total reduction average of porphyrins of $78.3 \%$, which implies a decrease in the population of $P$. acnes and an effective alternative for treating acne. 


\section{ACKNOWLEDGMENTS}

The authors thank all the individuals who participated in the in vivo studies in the assessment of the dermal safety of the lotion, and in the in vivo effectiveness evaluation of the cosmetic formulation, because these individuals made this research possible.

\section{CONFLICT OF INTEREST}

The authors declares that there is no conflict of interest.

\section{AUTHORS' CONTRIBUTION}

TM conducted formulation studies by establishing in vivo evaluation protocols, also participated in data analysis and wrote the manuscript. VP conducted the microbiological trials, coordinated the in vivo studies and helped to write the manuscript. Dermatologist Marcela Paredes conducted the dermatological assessment of the individuals before the instrumental evaluation study. All the authors read and approved the final manuscript.

\section{FUNDING}

The study was financed by Universidad Polit'cnica Salesiana and was the winner of the 2012 research call, in which the investigation was presented as a research topic of the Biotechnology Engineering career with the technical contribution of the Master of Science and Technology Cosmetics of the same institution.

\section{DATA AVAILABILITY}

The study data was recorded in Visiopor PP 34N software, Courage Khazaka Electronic, using codes that protect the identity of participating volunteer individuals.

\section{ETHICS STATEMENT}

All the research protocols were reviewed by the research committee of Universidad Polit 'cnica Salesiana, checking that they follow the national and international codes, oriented and justified within the scientific area, with noninvasive procedures that guarantee minimal risk to participants and protect the privacy and confidentiality of participants in the processes of data collection, handling and storage.

\section{REFERENCES}

1. Peral M.C., Huaman Martinez M.A., Valdez J.C. Bacteriotherapy with Lactobacillus plantarum in burns. Int. Wound J. 2009; 6(1):73-81. https://doi.org/10.1111/j.1742-481X.2008.00577.x.

2. Di Marzio L., Centi C., Cinque B., et al. Effect of the lactic acid bacterium Streptococcus thermophilus on stratum corneum ceramide levels and signs and symptoms of atopic dermatitis patients. Exp. Dermatol., 2003; 12(5): 615-620. https://doi.org/10.1034/j.1600-0625.2003.00051.x.

3. Pavicic T., Wollenweber U., Farwick M., Korting H.C. Anti-microbial and -inflammatory activity and efficacy of phytosphingosine: an In vitro and In vivo study addressing Acne vulgaris. Int. J. Cosmet. Sci., 2007; 29(3): 181-190. https://doi.org/10.1111/j.1467-2494.2007.00378.x.

4. Kang B.S., Seo J-G., Lee G-S., et al. Antimicrobial activity of enterocins from Enterococcus faecalis SL-5 against Propionibacterium acnes, the causative agent in Acne vulgaris, and its therapeutic effect. J. Microbiol., 2009; 47(1): 101-109. https://doi.org/10.1007/s12275-008-0179-y.

5. Al-Ghazzewi F.H., Tester R.F. Effect of konjac glucomannan hydrolysates and probiotics on the growth of the skin bacterium Propionibacterium acnes In vitro. Int. J. Cosmet. Sci., 2010; 32(2): 139-142. https://doi.org/10.1111/j.1468-2494.2009.00555.x.

6. Mottin V.H.M., Suyenaga E.S. An approach on the potential use of probiotics in the treatment of skin conditions: acne and atopic dermatitis. Int. J. Dermatol., 2018; 57(12): 1425-1432. https://doi.org/10.1111/ijd.13972.

7. Norma oficial mexicana. Norma oficial mexicana nom-039-ssa1-1993, bienes y servicios. Productos de perfumerna y belleza. Determinacion de los indices de irritacion ocular, primaria dermica y sensibilizacion. Mexico D.F.; 1993. http://www.salud.gob.mx/ unidades/cdi/nom/039ssa13.html. Accessed May 26, 2019.

8. Registro Oficial Suplemento 423. Ley Orgבnica de Salud.; 2006. https://www.todaunavida.gob.ec/ wp-content/uploads/downloads/2015/04/SALUDLEY_ORGANICA_DE_SALUD.pdf. Accessed May 26, $201 \overline{9}$.

9. Koepsell D., Ruiz M. tica de La Investigacion. 1st ed. Mexico D.F.: Editare, 2015.

10. Beauchamp T., Childress J. Principios de La tica Biom' dica. 7th ed. New York: Oxford University Press, 2013.

11. Prescott L.M., Harley J.P., Klein D.A., et al. Microbiolog ฉa. 4th ed. Boston: WCB McGraw Hill, 1999. 